\title{
THE AMINO-ACIDURIA IN GALACTOSAEMIA
}

\author{
BY \\ D. C. CUSWORTH, C. E. DENT and F. V. FLYNN \\ From University College Hospital and Medical School, London
}

(RECEIVED FOR PUBLICATION OCTOBER 25, 1954)

Excessive quantities of amino-acids have recently been found in the urine of infants with galactosaemia (Holzel, Komrower and Wilson, 1952; Bickel and Hickmans, 1952). At first sight, the occurrence of amino-aciduria in a condition known to be associated with severe liver damage would suggest that the amino-aciduria is of the 'overflow' variety, namely, that it occurs as the result of a rise of plasma level due to impaired deamination by the liver. However, the pattern of amino-acid excretion in galactosaemia does not resemble that of the already known overflow amino-acidurias of hepatic origin (Dent and Walshe, 1951). Moreover, preliminary investigations suggest that the mechanism is a renal one, presumably due to diminished tubular reabsorption of amino-acids by the kidney (Komrower, 1953). This is an interesting possibility since renal dysfunction has not previously been detected in this disease.

We describe here some investigations on a case of galactosaemia, a boy of 2 years who had been on a galactose-free diet from the age of 1 month. It was desired to reassess his tolerance to galactose with a view to possible modification of his very restricted diet, and this gave us the opportunity to investigate further the mechanism of the amino-aciduria under carefully controlled conditions.

\section{Case Record}

The full clinical record of this case is to be found on page 147. The patient had been under the care of Dr. Potter at the Queen Elizabeth Hospital for Children, and we are indebted to him for the opportunity to make this investigation. He was diagnosed as a case of galactosaemia at the age of 1 month and since then had been on a galactose-free diet. He was transferred for the purpose of this study to the Metabolic Ward, University College Hospital. On admission (September 10, 1953) he was 2 years of age, weighed $9 \cdot 2 \mathrm{~kg}$. and presented no abnormal physical signs but was somewhat backward mentally. His plasma urea was $42 \mathrm{mg}$. $/ 100 \mathrm{ml}$. and uncorrected urea clearances (UV/P) were 13.9 and 12 $\mathrm{ml} / \mathrm{min}$. The urine then contained no protein or reducing substances and the amino-acid chromatogram showed no amino-aciduria, the pattern of amino-acid excretion being the 'glycine pattern', the commonest of the normal variants (Dent and Walshe, 1954). A galactose tolerance test gave the results shown in Fig. 1.

He continued on the galactose-free diet which he had been having at the Queen Elizabeth Hospital, and from September 12,1953, the quantity of the diet was carefully standardized. This intake was exactly maintained throughout the patient's stay in the ward.

The diet comprised:

\section{GALACTOSE-FREE DIET}

(Total calories 1,150 )

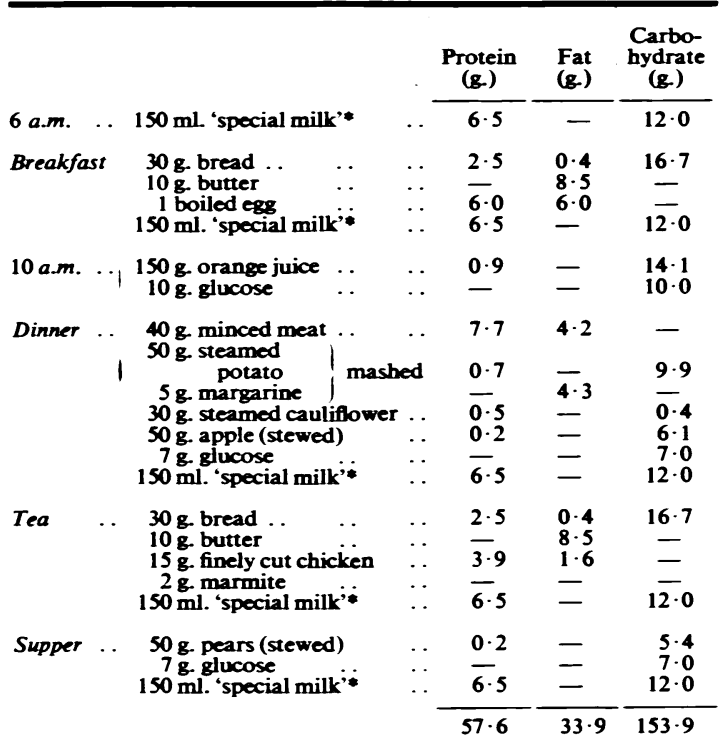

- The special milk comprised $36 \mathrm{~g}$. of 'casilan' (calcium caseinate) $60 \mathrm{~g}$. of glucose, made up to $750 \mathrm{ml}$. with tap water. (Komrower and Holzel have recently stated in a letter to the British Medical Journal of October 2, 1954, that 'casilan' contains small quantities of lactose.)

From September 18, 1953, he was given, in addition to his standard diet, $20 \mathrm{~g}$. galactose daily, taken divided with the meals. This quantity was chosen as being approximately the amo'int in the 1 litre of milk which a child of this age might be expected to consume. This was continued until October 2, 1953, after which the galactose supplement was omitted.

A few days after the galactose was begun the patient 


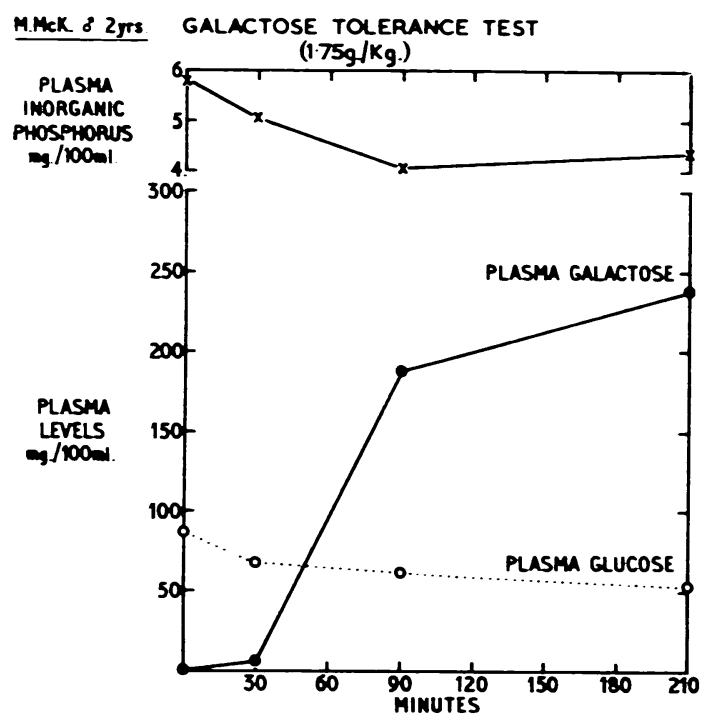

FiG. 1.-Galactose tolerance test.

became fretful and much more difficult to feed, and a week later some vomiting occurred which did not, however, persist. On withdrawing the galactose all his symptoms rapidly disappeared. Slight enlargement of the liver was detected after a few days; this disappeared later on returning to the galactose-free diet. After about four days on galactose a strong 'garlicky' smell appeared in his breath; this disappeared a few days later even though still taking galactose. On September 25 (eighth day of galactose) the 24-hour urinary excretion of galactose was $4.67 \mathrm{~g}$., equal to $23.4 \%$ of intake. On September 28 (eleventh day of galactose) serum flocculation tests showed: Colloidal red, weak positive; cephalin cholesterol, weak positive; thymol turbidity, 9 units with flocculation. Serum electrophoresis showed a normal pattern except for a slight increase of $\gamma$ globulin. Unfortunately the flocculation tests and electrophoresis were not done in the control period. Rather surprisingly, body weight was well maintained during the whole period of his time in the ward. He weighed $9.9 \mathrm{~kg}$. when the investigation was completed on October 11.

\section{Methods}

Collection of Urine. It was not possible to collect continuously 24-hour urines from the patient. Clearance determinations were, therefore, done entirely on timed specimens collected in each case over the same period of the day. With a nurse in continuous attendance, two conselutive accurately-timed urines were collected, each of about one and a half to two hours' duration, with a blood specimen at the approximate mid-point of each urine collection. The urine collector described by Black (1951) was used. The specimens for clearance determinations were obtained on admission and on two further occasions towards the end of the galactose supplement. We unfortunately could not obtain further clearance data during the final control period as the patient developed a sore which prevented us from using the urine collector.

As frequently as possible throughout the period of his stay, spontaneously passed, untimed urine specimens were also collected. These were used for sugar and amino-acid chromatograms and for the determination of amino-nitrogen indexes.

Biochemical Analyses. Plasma and urine $x$-aminonitrogen concentrations were determined by the methods of Hamilton and Van Slyke (1943) and Van Slyke, MacFadyen and Hamilton (1943) respectively. $x$-Aminonitrogen clearances (uncorrected for surface area) were calculated on the Van Slyke formula UV/P. The urine $x$-amino-nitrogen excretion was also calculated whenever it was possible on the basis of the $x$-amino-nitrogen

$$
\frac{\alpha \text {-amino-nitrogen }}{\text { total nitrogen }} \times 100
$$

indexes (Dent, 1947, 1954).

All our urine amino-acid chromatograms were prepared using phenol-ammonia and collidine-lutidinediethylamine as solvents (Dent, 1948), mostly in the apparatus of Datta, Dent and Harris (1950). The volume of urine applied to each $20 \mathrm{~cm}$. by $20 \mathrm{~cm}$. square contained $150 \mu \mathrm{g}$. of total nitrogen (e.g., $15 \mu \mathrm{l}$. for urine containing $1 \%$ total nitrogen). At the time of applying the urine to the square, $5 \mu \mathrm{l}$. of $0.01 \mathrm{M} x$-aminooctanoic acid was also added to act as position marker. The strengths of the final spots were assessed on an arbitrary scale of 10 units (Dent, 1947). For better identification of amino-acids, selected urines were also analysed on large (18 in. by $22 \mathrm{in}$.) chromatograms, using the volume containing $250 \mu \mathrm{g}$. total nitrogen.

The general method of Horrocks and Manning (1949) was used for one-way chromatograms of urine sugars. The solvent used, however, was a butanol-pyridine-water mixture (Hough, Jones and Wadman, 1950).

Plasma galactose and glucose concentrations were determined in duplicate on specimens of venous blood collected into fluoride. Total plasma-reducing power was first determined in the usual way by the HagedornJensen method. The value for plasma glucose was obtained by subtracting from this figure the plasmareducing power after incubation with yeast (Maclagan, 1940). The plasma galactose was determined from the plasma-reducing power remaining after fermentation. This was done by constructing a calibration curve for the final Hagedorn-Jensen thiosulphate titration from galactose solutions of known strength.

Urine galactose was determined by the standard Benedict method, using the factor for the reducing power of galactose, chromatograms having shown the absence of other reducing substances.

\section{Results}

The detailed findings are given in Table 1 and are summarized in Fig. 2. For purposes of comparison, urine $x$-amino-nitrogen indexes on five normal children aged 2-8 years are given in Table 2 as most previous work using this index has been on adults. 
TABLE 1

\begin{tabular}{|c|c|c|c|c|c|c|c|c|c|}
\hline \multirow{2}{*}{ Date } & \multirow{2}{*}{$\begin{array}{c}\text { Stage of } \\
\text { Investigation }\end{array}$} & \multirow{2}{*}{$\begin{array}{l}\text { Urine } \\
\text { Flow } \\
\text { (ml./min.) }\end{array}$} & \multicolumn{3}{|c|}{ a-Amino-nitrogen } & \multicolumn{2}{|c|}{ Urea } & \multicolumn{2}{|c|}{ Galactose } \\
\hline & & & $\begin{array}{c}\text { Plasma } \\
(\mathrm{mg} / 100 \mathrm{ml} .)\end{array}$ & $\begin{array}{l}\text { Clearance } \\
\text { (ml./min.) }\end{array}$ & $\begin{array}{l}\text { Urine } \\
\text { Index }\end{array}$ & $\begin{array}{c}\text { Plasma } \\
\text { (mg/ } / 100 \mathrm{ml} .)\end{array}$ & $\begin{array}{l}\text { Clearance } \\
\text { (ml./min.) }\end{array}$ & $\begin{array}{c}\text { Plasma } \\
(\mathrm{mg} / 100 \mathrm{ml} .)\end{array}$ & $\begin{array}{l}\text { Clearance } \\
\text { (ml./min.) }\end{array}$ \\
\hline Sept. 14 & Control period & $\begin{array}{l}0 \cdot 98 \\
0 \cdot 78\end{array}$ & $\begin{array}{l}3 \cdot 33 \\
3 \cdot 34\end{array}$ & $\begin{array}{l}0 \cdot 63 \\
0 \cdot 48\end{array}$ & $\begin{array}{l}0 \cdot 58 \\
0 \cdot 70\end{array}$ & $\begin{array}{l}42 \\
42\end{array}$ & $\begin{array}{l}13 \cdot 9 \\
12 \cdot 0\end{array}$ & & \\
\hline Sept. 18 & Control period & & & & $0 \cdot 52$ & & & & \\
\hline Sept. 28 & 11 days on galactose & $\begin{array}{l}0 \cdot 27 \\
0 \cdot 30\end{array}$ & $\begin{array}{l}4 \cdot 00 \\
4 \cdot 61\end{array}$ & $\begin{array}{l}1 \cdot 81 \\
1 \cdot 82\end{array}$ & $\begin{array}{l}1 \cdot 69 \\
2 \cdot 22\end{array}$ & $\begin{array}{l}45 \\
42\end{array}$ & $\begin{array}{l}17 \cdot 9 \\
19 \cdot 1\end{array}$ & $\begin{array}{l}43^{*} \\
55^{*}\end{array}$ & $\begin{array}{l}9 \cdot 65 \\
9 \cdot 85\end{array}$ \\
\hline Oct. 2 & 15 days on galactose & $0 \cdot 34$ & $5 \cdot 53$ & $2 \cdot 06$ & $3 \cdot 30$ & 51 & $13 \cdot 0$ & & \\
\hline Oct. 7 & $\begin{array}{l}5 \text { days after galactose } \\
\text { was stopped }\end{array}$ & & & & $1 \cdot 03$ & & & & \\
\hline Oct. 10 & $\begin{array}{l}8 \text { days after galactose } \\
\text { was stopped }\end{array}$ & & & & 0.62 & & & & \\
\hline
\end{tabular}

* Corresponding plasma glucose concentrations 95 and $67 \mathrm{mg} . / 100 \mathrm{ml}$.

Plasma a-amino-nitrogen values tre corrected for plasma urea. All clearances cakculated from formula UV/P. Only one plasma specimen could be obtained on October 2.

The figure is self-explanatory except for the curve showing the amino-aciduria. The units taken for this represent the summation of all the colour values (on our arbitrary scale) of ninhydrin reacting spots. Photographs of chromatograms taken throughout the period of the investigation show in more detail the urine amino-acid changes actually taking place (Fig. 3). A large chromatogram of the urine on October 2, 1953, when the strongest amino-aciduria was occurring, showed the typical galactosaemic pattern, namely, a relatively large increase in the small-molecular weight amino-acids especially serine, glycine, threonine and alanine, with lesser increases in glutamine, valine, the leucines and tyrosine. It

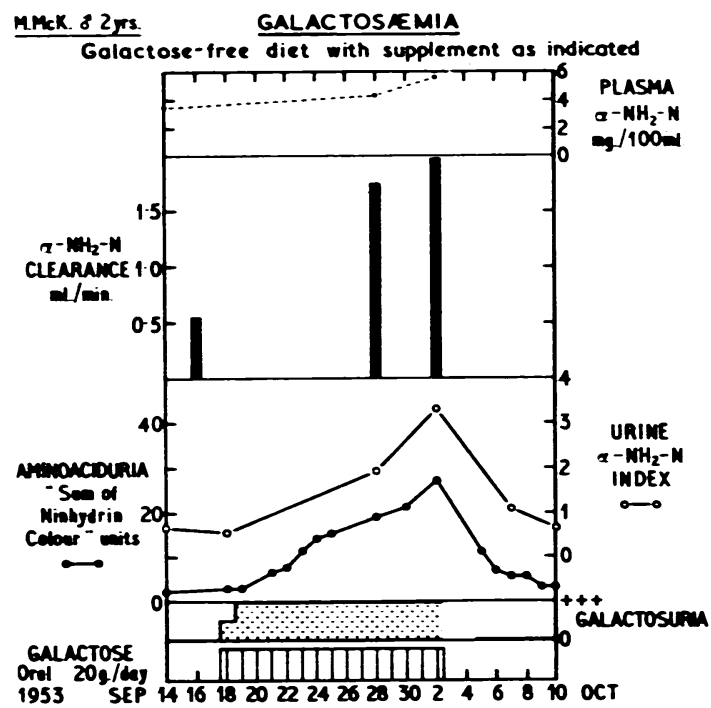

Fic. 2-Amino-acid clearances and excretions before, during and after addition of galactose to the patient's diet. may be that the amino-aciduria would become stronger if the galactose were taken for a longer period. The pattern is, however, very similar to that already illustrated for the two cases described by Holzel et al. (1952). The pattern illustrated by Bickel and Thursby-Pelham (1954) for the urine of a galactosaemic child shows certain differences, notably a relative increase in aspartic and glutamic acids and a decrease in glutamine. These differences could be due to artifacts of urine storage, as we have considerable experience of such changes occurring in stored specimens and appear to have produced a similar artifact, the increase of glutamic acid, in the specimen of October 2 shown on Fig. 3.

In every case when the urine reduced Benedict's reagent (Fig. 2), this was shown by paper chromatography to be due to galactose alone.

TABLE 2

URINE $x$-AMINO-NITROGEN INDEXES OF NORMAL CHILDREN

\begin{tabular}{cccc}
\hline Subject* & Age & Sex & Index \\
\cline { 2 - 4 } C. & $2 \frac{1}{12}$ & F. & $1 \cdot 77$ \\
Sa. & $4 \frac{2}{12}$ & F. & $1 \cdot 46$ \\
T. & 6 & M. & $1 \cdot 10$ \\
Su. & $7 \frac{4}{1 \frac{2}{12}}$ & F. & $0 \cdot 96$ \\
A. & $8 \frac{1}{12}$ & F. & $1 \cdot 34$ \\
\hline
\end{tabular}

- All are siblings.

Discussion

Galactosaemia is a condition in which a precise clinical picture is associated with a defect in which the patient's ability to metabolize galactose is grossly impaired. It is of interest that two patients have been described who appear to have developed increased tolerance when they were examined at the age of 7 years (Townsend, Mason and Strong, 1951; Bray, Isaac and Watkins, 1952). It can be seen, 
however, from Figs. 1 and 2 that our patient was still grossly intolerant of galactose at the age of 2 years after having been kept for nearly all this time on a galactose-free diet. He clearly needs to be maintained for a much longer period on this diet.

We must stress that the block in galactose metabolism was not complete, as also found by other workers, since our patient's 24-hour urine output of galactose was only $23 \%$ of his intake on the occasion we determined it. There was also a fall in plasma inorganic phosphorus during his galactose tolerance test (Fig. 1)-indirect evidence that he was then rapidly forming glycogen from circulating galactose and glucose. Like other workers we have also noted hypoglycaemia whenever plasma galactose was raised, and consider this a possible cause of the mental retardation and other symptoms, as originally suggested by Mason and Turner (1935).

The summarized results in Fig. 2 show that immediately after taking galactose by mouth a heavy galactosuria was induced. We presume that this disappeared equally rapidly when the galactose was

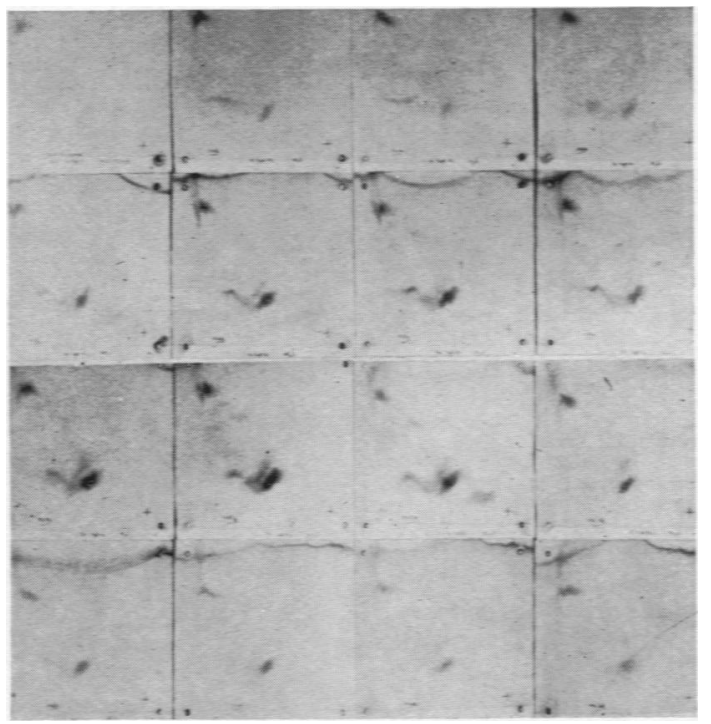

Fig. 3.-Photographs of serial chromatograms carried out during the course of this investigation.

Each square represents the small chromatogram carried out on the patient's urine as described in the text.

From left to right the dates of the urine collections are as follows: September 14 and 18, 1953 (galactose addition to diet begun on 18th) September 19, 21, 22, 23, 24, 25, 28, 30, October 2, 1953 (after October 2 galactose was stopped); October 5, 6, 7, 8, 10, 1953.

The onset and disappearance of the amino-aciduria a few days after the beginning and ending of the galactose addition are readily seen as a strengthening and increase in number of the amino-acid spots. Identifications of the amino-acids were done on larger chromatograms than these as the spots are less well defined on small chromatograms. The spot on the top left-hand corner of each square is due to a-amino-octanoic acid, added as a marker. discontinued, although unfortunately we were unable to obtain urine specimens until the third day after the galactose had been stopped. The galactose also induced a marked amino-aciduria, as has been found by other workers. The development of this, however, was slow in comparison with that of the galactosuria; indeed the amino-acid excretion was still increasing slowly on the fifteenth (and last) day of galactose administration. Not only did it take longer to appear, but also to disappear, for the urine amino-acid excretion did not return to normal until seven days after withholding galactose (Fig. 3). These changes were detected clearly by our arbitrary measurement of ninhydrin colour on the chromatograms and by the more accurate quantitative measurement of $x$-amino-nitrogen indexes (Fig. 2).

As far as the mechanism of the amino-aciduria is concerned, the clearance measurements (uncorrected for body size) show a marked rise in $x$-aminonitrogen clearance of from $0.5 \mathrm{ml} . / \mathrm{min}$. in control periods to $2 \mathrm{ml} . / \mathrm{min}$. at the height of the aminoaciduria. This is clearly the main cause of the amino-aciduria, and, in the absence of comparable changes in the simultaneous urea clearances, it is almost certainly due to diminished renal tubular reabsorption of amino-acids. There was a slow rise in the plasma $x$-amino-nitrogen also, though the level never exceeded the upper limit of normal. However, as the patient was so carefully controlled as to dietary intake it is possible that the rise is significant and an indication of some slight degree of liver damage. It could contribute to the amino-aciduria, but only in small part, as normal subjects fed casein to produce similar slight rises in plasma level showed only a very slight rise in $x$ amino-nitrogen clearance (Dent and Fowler, 1954, and further unpublished work). Bickel and Thursby-Pelham (1954), however, found grossly raised plasma $x$-amino-nitrogen levels of $8 \cdot 3$ and $8.8 \mathrm{mg} . / 100 \mathrm{ml}$. in their case. We have never found such high values in cases of galactosaemia, and, in fact, have only encountered such figures in terminal cases of liver disease, and then only when there is almost complete destruction of the liver parenchyma.

A further argument against the possibility that liver damage contributes appreciably to the aminoaciduria concerns the pattern of urinary amino-acid excretion found in these cases. In mild liver disease of various aetiologies, the amino-aciduria mainly comprises relative increases in some of the following amino-acids and closely related compounds: cystine, taurine, $\beta$-amino-isobutyric acid, methylhistidine, ethanolamine and methionine (Den and Walshe, 1951; Walshe, 1953). Such was no 
the case with our patient nor with those of Holzel et al. (1952).

It is interesting to compare and contrast the mechanisms of the galactosuria and of the aminoaciduria. The galactosuria occurred as soon as the plasma galactose level was raised and stopped as soon as the level returned to normal, strongly suggesting that it resulted from the rise in plasma level. The amino-aciduria, on the other hand, was probably due to some chemical ('toxic') action on the renal tubular cells-possibly due to galactose itself-several days being required to produce and to recover from this 'toxicity'. This would account for the failure to observe amino-aciduria in galactosaemic patients maintained on a galactose-free diet when they are given galactose on one day only (Bickel and Hickmans, 1952; Bickel and ThursbyPelham, 1954).

Galactosaemia is now believed to be an inborn error of metabolism. If this is so, we must postulate here that the amino-aciduria is not a direct effect of the abnormal gene, as for instance is the case in cystinuria and in some other inborn renal tubular reabsorption abnormalities, such as $\beta$-aminoisobutyric aciduria (Crumpler, Dent, Harris and Westall, 1951; Harris, 1953). The amino-aciduria of galactosaemia must be a later change induced by the primary abnormality and is therefore somewhat akin to the amino-aciduria which occurs in patients with Wilson's disease. This latter amino-aciduria (as also the other signs of the disease) does not appear to be present from birth but to result from the action over many years of an environmental factor to which they have an inborn sensitivity and which is in Wilson's disease presumably an intoxication by dietary copper. We think it is highly significant that a delay in appearance of the amino-aciduria in a case of the Fanconi syndrome has also been recently described (Bickel and ThursbyPelham, 1954). It is well known that the other signs and symptoms of this syndrome show a similar delay in onset.

\section{Summary}

A boy of 2 years of age with galactosaemia has been studied.

He had an abnormal galactose tolerance curve after having been nearly two years on a galactosefree diet.

Under carefully controlled conditions, he was given $20 \mathrm{~g}$. a day of galactose by mouth for 15 days. The amino-aciduria slowly developed while he received the galactose and slowly disappeared after it was stopped.

The amino-aciduria occurred mainly as a result of decreased renal tubular reabsorption of aminoacids.

We wish to thank Sister C. Turner for supervising the nursing arrangements, Miss D. Tuck for preparing the diet, and Drs. J. Anderson and B. Senior for medical assistance. We also thank Mr. V. K. Asta for the diagrams, and Mr. Q. Bligh for the photographs.

REFERENCES

Bickel, H. and Hickmans, E. M. (1952). Archives of Disease in Childhood, 27, 348.

and Thursby-Pelham, D. C. (1954). Ibid., 29, 224

Black, J. A. (1951). lbid., 26, 618.

Bray, P. T., Isaac, R. J. and Watkins, A. G. (1952). Ibid., 27, 341

Clay, P. R. and Potter, C. T. (1955). Ibid., 30, 147.

Crumpler, H. R., Dent, C. E., Harris, H. and Westall, R. G. (1951) Nature, Lond. 167, 307 .

Datta, S. P., Dent, C. E. and Harris, H. (1950). Science, 112, 621

Dent, C. E. (1947). Biochem. J., 41, 240.

(1948). Ibid., 43, 169.

(1954). Exp. Med. Surg., 12, 229

and Fowler, D. I. (1954). Ibid., 12, 230.

and Walshe, J. M (1951) Liver Disease, p. 22 ad S Sherlock and G. E. W. Wolstenholme. Ciba Foundation Symposium, London.

London. (1954). Brit. med. Bull., 10, 247.

Hamilton, P. B. and Van Slyke, D. D. (1943). J. biol. Chem., 150, 231.

Harris, H. (1953). Ann. Eugen., Camb., 18, 43.

Holzel, A., Komrower, G. M. and Wilson, V. K. (1952). Brit. med. $J .1,194$.

Horrocks, R. H. and Manning, G. B. (1949). Lancet, 1, 1042.

Hough, L., Jones, J. K. N. and Wadman, W. H. (1950). J. chem. Soc. p. 1702.

Komrower, G. M. (1953). Arch. franc. Pédiat., 10, 185

Maclagan, N. F. (1940). Quart. J. Med., 9, 151.

Mason, H. H. and Turner, M. E. (1935). Amer. J. Dis. Child. $50,359$.

Townsend, E. H., Mason, H. H. and Strong, P. S. (1951). Pediatrics, 7,760 .

Van Slyke, D. D., MacFadyen, D. A. and Hamilton, P. B. (1943) J. biol. Chem., 150, 251 .

Walshe, J. M. (1953). Quart. J. Med., 22, 483 